\title{
Diving into Debt: A Study on Factors Related to Debt Risk Score in Toronto
}

\section{AUTHORS: Anupya Pamidimukkala, Fei Dong, Jessica Ip, Pamela Zeng \\ SCHOOL: Earl Haig Secondary School}

\section{Abstract}

This study aimed to find the correlations between data found regarding debt risk and the 140 neighbourhoods in Toronto, Ontario. Debt risk was compared with select variables from available data, including education, health, environment, housing, economics, demographics, transportation, recreation, and safety. The purpose of this study was to help civilians and the government identify possible factors that lead to higher debt risk, as well as find solutions to reduce it.

The data was retrieved from Open Data Toronto. A simple linear regression model was built to determine the factors that have a seemingly great correlation with debt risk. It was concluded that the percentage of people who receive social assistance, the percentage of people who applied for rent banks, and the number of reported sexual assaults in a neighbourhood had a positive correlation with increased debt risk. The result is that an age-adjusted rate of people who received breast cancer screening had a negative correlation with increased debt risk.

Through the results, several solutions could be proposed to reduce debt risk. More education on safety and health can enable citizens to become more responsible and aware of their financial state. Giving other forms of aid that are not monetary may be beneficial in helping people get out of debt and become more financially independent.

\section{Key Words}

Debt, Toronto, Neighbourhoods, Big Data, Debt Risk

\section{Introduction}

There are several factors that can cause poor financial responsibility. Debt Risk Score is a quantitative measure of the economic status of a neighbourhood. It is an index value provided by the TransUnion Canada which indicates the likelihood of missing three consecutive loan payments. A low score (under 707) indicates a higher risked area. A high score (over 769) indicates a low risked area. These scores are calculated for non-mortgage consumer debt in lines of credit, credit cards, automobile loans, and instalment loans (2). Many variables were observed to determine if they had a correlation or impact on the Debt Risk Score (2).

A social assistance recipient is considered anyone who qualifies for Ontario Works, Temporary Care, Ontario Disability Support Program, or Special Assistance programs (2). The count is done by members, not cases. Rent Bank is a program that provides limited, interest free loans to those who face eviction for rental arrears. The program also provides emergency deposit loans to people who require first and last month's rent to move to more affordable housing (3).

Through the results, it can be determined if there is a relationship between the number of recipients and applicants of these financial assistive programs, and the Debt Risk Score of the neighbourhood. This can lead to further studies on whether or not the city's finances are being spent in the right neighbourhoods and on the people that require and will benefit from these resources.

The number of sexual assaults (4) and an age adjusted rate (out of 100) of people between ages 50 to 59 who received breast cancer screening (5) are also studied in this paper. These results can show the relationship between the Debt Risk Score and the health and safety of the city. It can also help create new possible solutions to increase Debt Risk Score. This data was collected in 2011.

\section{Materials and Methods}

The analysis was completed using SAS Studio Edition. A master table was made which combined variables from various data sources containing information regarding Toronto in 2011, sorted into neighbourhoods. The master table contained data from education, health, environment, housing, economics, demographics, transportation, recreation, and safety (2-10). 


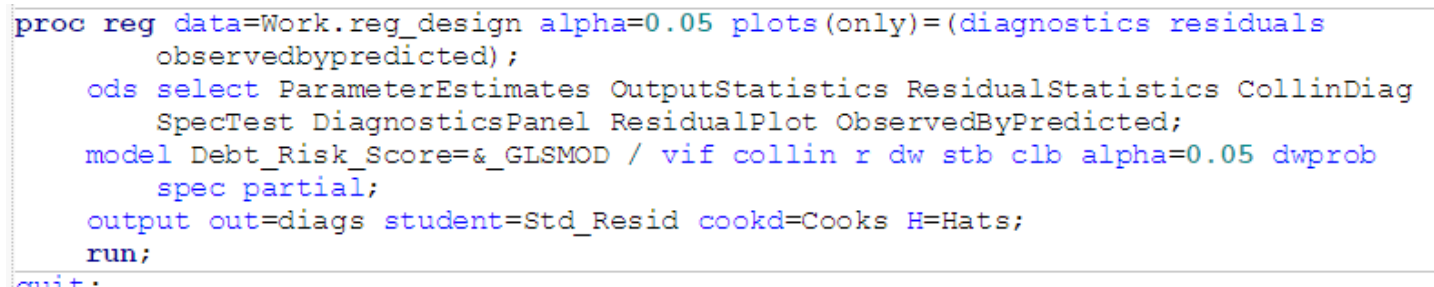

Figure 1: Code used to run the linear regression model.

Following that, the data was manipulated. A population density variable was added by dividing the total population of a neighbourhood over the total square kilometer of area of the neighbourhood. Population related variables were divided over the total population to get a percentage, so that it was comparable with other neighbourhoods. It took into account any neighbourhoods that might have had a relatively high population density.

A simple linear regression model was then built, with Debt_Risk Score as the dependent variable, and all continuous variables in the master table as independent variables. Forward selection was used to select impactful variables with a $5 \%$ significance level.

Nine variables were found to be statistically significant for Debt_ Risk_Score on a $5 \%$ significance level.

After these findings, four variables were chosen for further analysis in this report. The others were disregarded for this study.

The variables chosen for analysis were number of sexual assaults reported (Sexual_Assaults) (10), an age adjusted rate (out of 100) of people between ages 50 to 59 who received breast cancer screening (Breast_Cancer_Screen) (5), percentage of neighbourhood population applying to Rent Bank (Percent_RBA), and percentage of neighbourhood population receiving social assistance (Percent_Of_SA).

\section{Results}

In Figure 3, there was an apparent a correlation between the Debt Risk Score of a neighbourhood (Y-axis) and the number of sexual assaults (X-axis). This was confirmed by the model (Figure 2) with the coefficient -0.40087 , which showed a clear negative trend. This result depict a seemingly linear relationship between the amounts of sexual assaults to the financial stability in a neighbourhood. A vast number of sexual assaults came from communities with high Debt Risk Scores, insinuating that lower financial stability led to a higher sexual assault rate.

On the other hand, there seemed to be a positive linear relationship between Debt Risk Score (Y-axis) and age adjusted rate (out of 100) for breast cancer screenings (labelled on each bubble). This was also shown in Figure 2 with a coefficient of 0.46895 , but the $p$ value of 0.0530 indicated that it was not conclusive evidence. Only 50-59 year old people's data were graphed since they were at a higher risk of breast cancer and were expected to be screened frequently. A higher Debt Risk Score was representative of neighbourhoods with greater financial stability, therefore wealth. The wealthy had access to better education and were generally more informed about issues related to health, which could lead to the health-conscious choice to undergo breast cancer screenings. The communities with the highest number of breast cancer screenings had a lower chance of not being able to pay back their debt, implying that

\begin{tabular}{|c|c|c|c|c|c|c|c|c|c|c|}
\hline \multicolumn{11}{|c|}{ Parameter Estimates } \\
\hline Variable & Label & DF & $\begin{array}{l}\text { Parameter } \\
\text { Estimate }\end{array}$ & $\begin{array}{r}\text { Standard } \\
\text { Error }\end{array}$ & t Value & $\operatorname{Pr}>|t|$ & $\begin{array}{r}\text { Standardized } \\
\text { Estimate }\end{array}$ & $\begin{array}{r}\text { Variance } \\
\text { Inflation }\end{array}$ & \multicolumn{2}{|c|}{$95 \%$ Confidence Limits } \\
\hline Intercept & Intercept & 1 & 727.21260 & 20.65165 & 35.21 & $<.0001$ & 0 & 0 & 686.35577 & 768.06942 \\
\hline Child_Care_Spaces & Child_Care_Spaces & 1 & 0.03370 & 0.01022 & 3.30 & 0.0013 & 0.08607 & 1.11401 & 0.01348 & 0.05391 \\
\hline Breast_Cancer_Screen & Breast_Cancer_Screen & 1 & 0.48885 & 0.24011 & 1.85 & 0.0530 & 0.08328 & 2.38788 & $-0.0060 \theta$ & 0.84398 \\
\hline Percent_Mid_Century_ & Percent_Mid_Century_ & 1 & 0.21738 & 0.05848 & 3.72 & 0.0003 & 0.12902 & 1.58226 & 0.10188 & 0.33309 \\
\hline Percent_RBA & Percent_RBA & 1 & -10188 & 2262.54971 & -4.50 & $<.0001$ & -0.17691 & 2.02719 & -14864 & -5711.41943 \\
\hline Fires___Fire_Alarms & Fires___Fire_Alarms & 1 & 0.02651 & 0.00634 & 4.18 & $<.0001$ & 0.18388 & 2.54074 & 0.01396 & 0.03905 \\
\hline Sexual_Assaults & Sexual_Assaults & 1 & -0.40087 & 0.08095 & -4.95 & $<.0001$ & -0.20503 & 2.25085 & -0.56101 & -0.24072 \\
\hline Percent_Of_SA & Percent_Of_SA & 1 & -308.01956 & 22.53564 & -13.67 & $<.0001$ & -0.67183 & 3.17263 & -352.60363 & $-263.4354 \theta$ \\
\hline Percent_20_29 & Percent_20_20 & 1 & -67.68194 & 28.93481 & -2.34 & 0.0209 & -0.10910 & 2.85665 & -124.82589 & -10.43788 \\
\hline Percent_50_59 & Percent_50_59 & 1 & 159.04526 & 65.14711 & 2.44 & 0.0160 & 0.10011 & 2.20818 & $30.1594 \theta$ & 287.83103 \\
\hline
\end{tabular}

Figure 2: Results table from SAS. 
people with higher Debt Risk Scores make more informed choices. It might be concluded that people who were conscious of their health were also generally more punctual in paying back their debt and maintaining their financial status.

People with higher Debt Risk Scores (Yaxis) had a low percentage of rent bank applications in a neighbourhood (bubble size). This result made sense due to the fact that the superior ability to pay back debt (as suggested by the Debt Risk Score) was evident as a greater percentage of people was able to pay rent without any extra loans. The less financially-stable neighbourhoods showed a greater number of Rent Bank applications submitted, since they required the interestfree loans and emergency rental deposit loans that the Rent Bank Program was able to offer them.

There was a negative correlation between Debt Risk Score (Y-axis) and percentage of social assistance recipients in a neighbourhood (bubble colour) in Figure 3. As the Debt Risk Score decreased, the percentage of social assistance recipients increased. These recipients were qualified for Ontario Works, Temporary Care (OW), Ontario Disability Support Program (ODSP), or Special Assistance (ODSP/ OW). It could be conclud- ed from this graph that more social assistance was given to the neighbourhoods that had lower Debt Risk Scores, which was reflective of their financial requirements.

\section{Discussion}

The number of sexual assaults seemed to have a negative correlation with the Debt Risk Score. It was possible that people in neighbourhoods with more crimes, such as sexual assaults, were committing these crimes partially due to the added pressures of being in debt, leading to unconventional behaviour. An inadequate confidence in their neighbourhood may also prevent people from working at their full productivity.

The positive correlation between Breast Cancer Screenings and Debt Risk Score implied that people who were more conscious of their health were less likely to be in debt. Better health management could also lead to increased confidence and motivation to take on other responsibilities in life. Healthy members of the community would be able to obtain higher levels of productivity and have a better chance in staying out of debt.

When there was a growth in the percentage of people who received social assistance, there appeared to be a decrease of Debt Risk Score. Similarly, there was an increase in the percentage of people applying for benefits of the Rent Bank Program in neighbourhoods with lower Debt Risk Scores. This could mean that people who received financial assistance have a higher risk of being in debt. Based on this correlation, it could be concluded that those who received aid were the ones who require financial help. However, it also indicated that monetary welfare by itself may not financially benefit the recipients, as they may become dependent on the assistance.

There could be many solutions that will change the variables, 
which in turn may affect the Debt Risk Score. However, it was inconclusive whether the debt risk of a neighbourhood was the cause or the effect. Improved financial health in the city may have an effect on the other variables as well.

\section{Appendix}

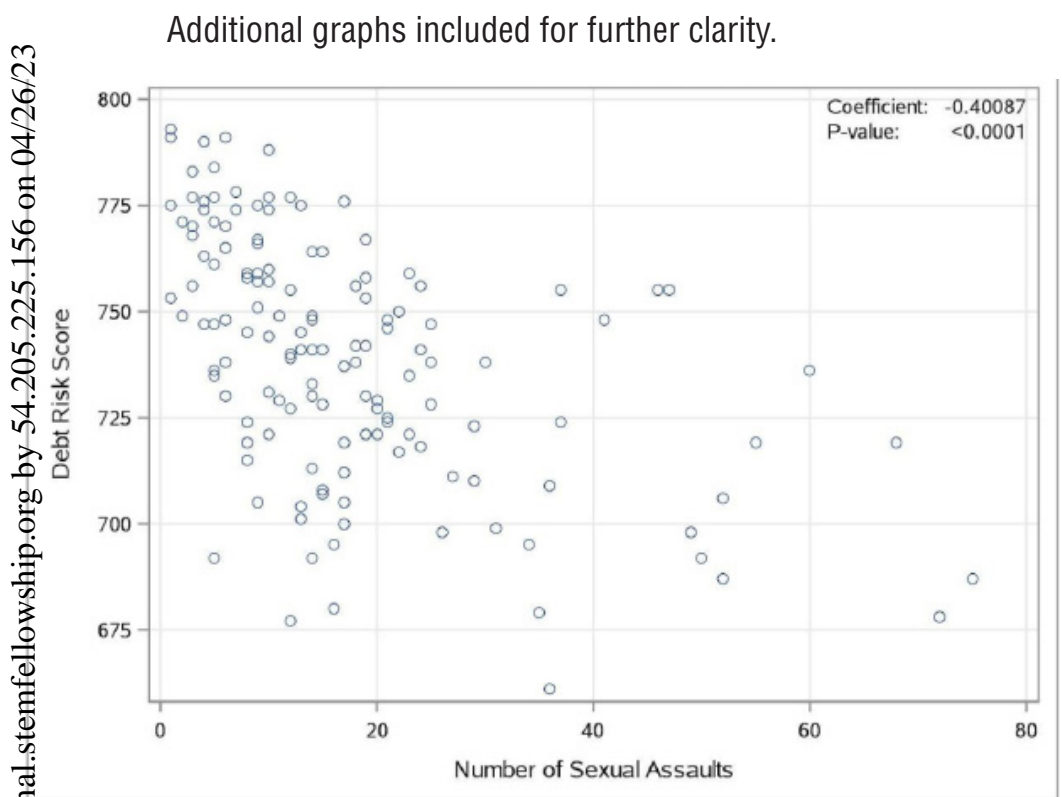

\section{Äppendix 1: Debt risk score vs. sexual assaults}

This scatter plot shows the relationship between Debt Risk Score 2011.

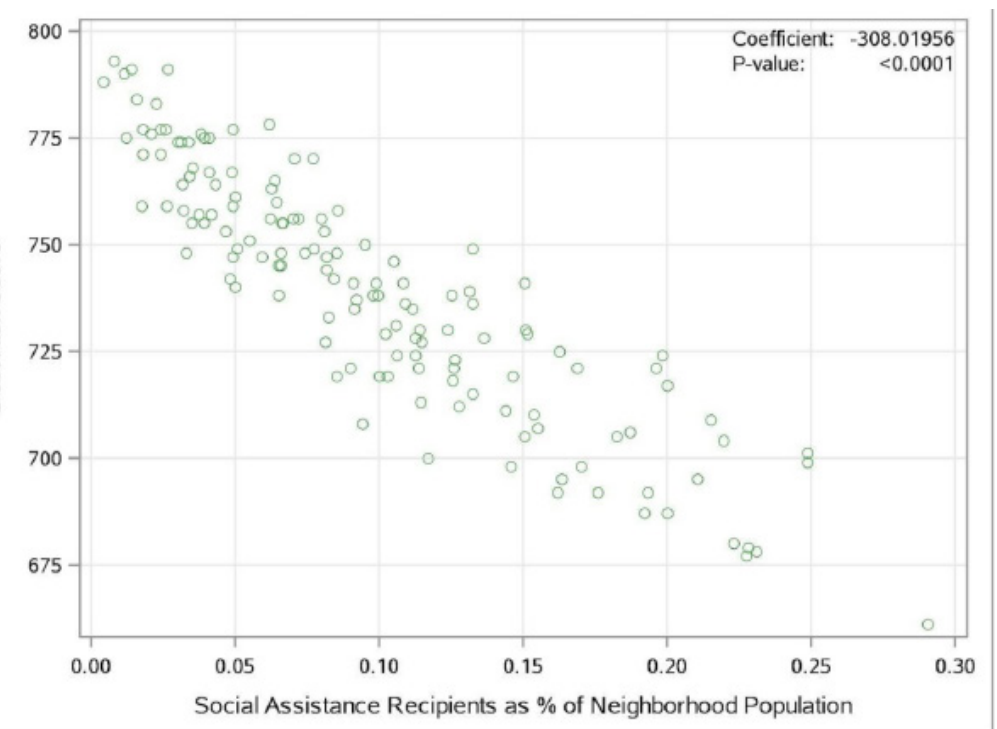

Appendix 3: Debt risk score vs. social assistance

This scatter plot shows the relationship between Debt Risk Score and percentage of the neighbourhood population that received social assistance in 2011.

\section{Conclusion}

One way to reduce debt risk is to educate citizens on financial math, which can be achieved by integrating it into school curriculums. Hosting career workshops is another option. More scholarships could also be granted as it enables people to gain an education that could lead to higher earning jobs.

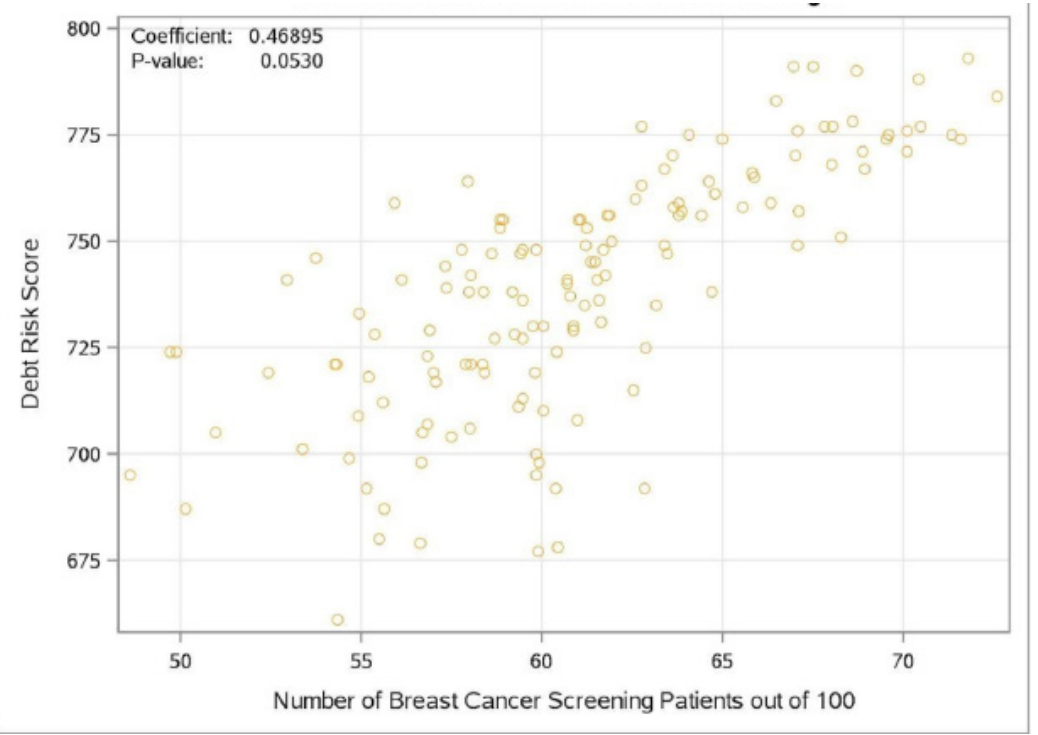

Appendix 2: Debt risk score vs. breast cancer screenings

This scatter plot shows the relationship between Debt Risk Score and age adjusted rate (out of 100) of Breast Cancer Screenings of people 5059 years of age in 2011.

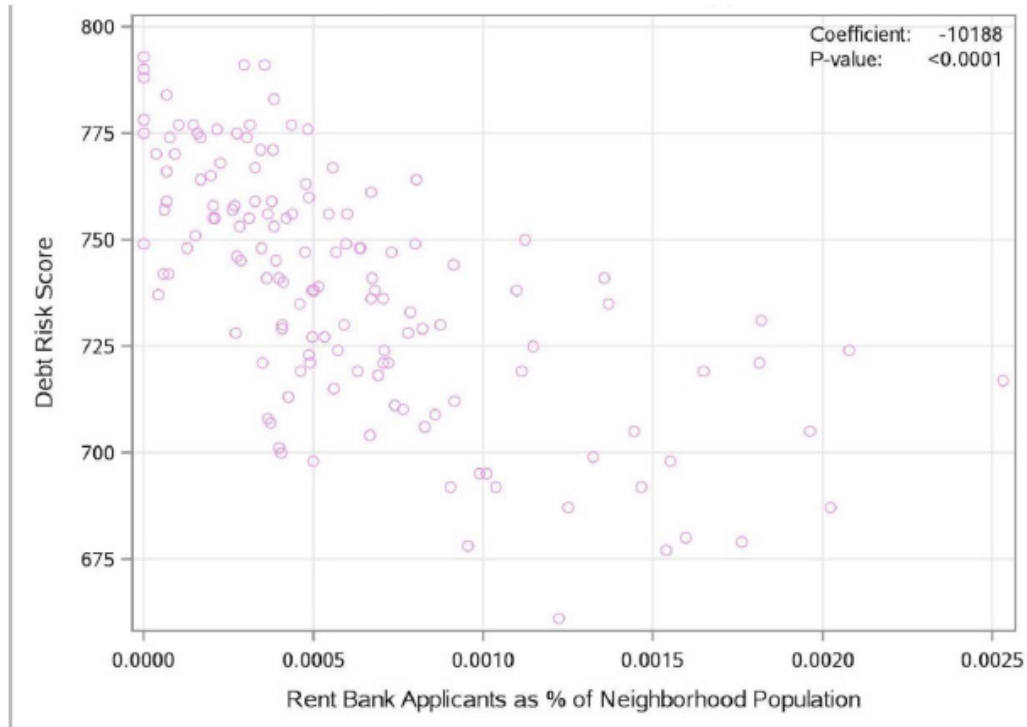

Appendix 4: Debt risk score vs. bank applicants

This scatter plot shows the relationship between Debt Risk Score and percentage of the neighbourhood population who were Rent Bank applicants in 2011. 
Other methods of government intervention may also reduce debt risk. Minimum wage proportional to the cost of living, stricter rent ceilings, lower interest rates, and non-financial incentives may lead to less reliance on social assistance and Rent Bank, which may have an effect in lowering debt risk. These policies may help make it more affordable to live within the city.

City projects such as infrastructure building can provide jobs and help the city in the long run. By implementing some of the solu tions, individuals may be able to make better financial decisions. Citizens would feel more confidence and motivation to take on other responsibilities in life, leading to higher levels of productivity.

Better government policies may be able to improve the quality of living within the city, which in turn could mean that citizens could then afford to care about their health. There could be less incentive to commit crime because citizens would be able to provide for themselves through legal means. By contributing to society, they may have a better chance of staying out of debt. The implementation of these solutions may thus lead to a more prosperous, healthier and safer city.

Future research could be done by tracking Debt Risk Score and these four factors over several years to see if there is a trend over time. More data could also be collected about education and surveillance levels, as these factors have a possible correlation to increase Debt Risk Score. An analysis of this data could contribute evidence to this hypothesis.

\section{Acknowledgements}

We would like to thank our mentor Jos Polfliet for his support in introducing us to the world of SAS. We would also like to thank Sacha Noukhovitch and Yang Liu for their ongoing support.

\section{References}

1. Toronto neighbourhoods list [Internet]. Toronto: City Of Toronto; c1998-2015. Avaliable from: http://www1.toronto.ca/wps/portal/contentonly?v gnextoid=100c861b9fdb1410VgnV

CM10000071d60f89RCRD

2. Wellbeing Toronto - economics [dataset]. [updated 2014 Dec 17; cited 2015 Dec 19]. Open Data - Toronto. Avaliable from: http://www1. toronto.ca/wps/portal/contentonly?vgnextoid=aec380ece073b410VgnVCM10 000071d60f89RCRD\&vgnextchannel=1a66e03bb8d1e310VgnVCM10000071d60f89RCRD

3. Wellbeing Toronto - housing [dataset]. [updated 2015 Apr 2; cited 2015 Dec 19]. Open Data - Toronto. Avaliable from: http://www1.toronto.ca/ $\mathrm{wps} /$ portal/contentonly?vgnextoid=f5c12c077444d410VgnVCM10000071 d60f89RCRD\&vgnextchannel=1a66e03bb8d1e310 VgnVCM10000071 d60f89RCRD

4. Wellbeing Toronto - safety [dataset]. [updated 2014 Dec 17; cited 2015 Dec 19]. Open Data - Toronto. Avaliable from: http://www1.toronto.ca/ wps/portal/contentonly?vgnextoid=b3ff80ece073b410VgnVCM10000071d60f89RCRD\&vgnextchannel=1a66e03bb8d1e310VgnVCM10000071 d60f89RCRD

5. Wellbeing Toronto - health [dataset]. [updated 2014 Dec 17; cited 2015 Dec 19]. Open Data - Toronto. Avaliable from: http://www1.toronto.ca/ wps/portal/contentonly?vgnextoid=b3e280e59381b410VgnVCM10000071d60f89RCRD\&vgnextchannel=1a66e03bb8d1e310VgnVCM1000007 1d60f89RCRD

6. Wellbeing Toronto - environment [dataset]. [updated 2014 Dec 17; cited 2015 Dec 19]. Open Data - Toronto. Avaliable from: http://www1. toronto.ca/wps/portal/contentonly?vgnextoid=67f6d05685a0c410VgnVCM1

0000071d60f89RCRD\&vgnextchannel=1a66e03bb8d1e310VgnVCM10000071d60f89RCRD

7. Wellbeing Toronto - demographics [dataset]. [updated 2014 Dec 17; cited 2015 Dec 19]. Open Data - Toronto. Avaliable from: http://www1. toronto.ca/wps/portal/contentonly?vgnextoid=4482904ade9ea410VgnVCM

10000071d60f89RCRD\&vgnextchannel=1a66e03bb8d1e310VgnVCM10000071d60f89RCRD

8. Wellbeing Toronto - transportation [dataset]. [updated 2014 Dec 17; cited 2015 Dec 19]. Open Data - Toronto. Avaliable from: http://www1. toronto.ca/wps/portal/contentonly?vgnextoid=e1ad842971e5a410VgnVCM1

0000071d60f89RCRD\&vgnextchannel=1a66e03bb8d1e310VgnVCM10000071d60f89RCRD

9. Wellbeing Toronto - recreation [dataset]. [updated 2014 Dec 17; cited 2015 Dec 19]. Open Data - Toronto. Avaliable from: http://www1. toronto.ca/wps/portal/contentonly?vgnextoid=36c1d914ec71b410VgnVCM10000071d60f89RCRD\&vgnextchannel=1a66e03bb8d1e310VgnVC M10000071d60f89RCRD

10. Wellbeing Toronto - education [dataset]. [updated 2014 Dec 17; cited 2015 Dec 19]. Open Data - Toronto. Avaliable from: http://www1. toronto.ca/wps/portal/contentonly?vgnextoid=a287d05685a0c410VgnVCM1

0000071d60f89RCRD\&vgnextchannel=1a66e03bb8d1e310VgnVCM10000071d60f89RCRD 


\section{REVIEW}

\section{by Dr. Marcelo Ponce, SciNet, University of Toronto}

In this paper the authors, by using publicly available datasets, attempt to expose correlations between several variables related to debt risk obtained for 140 neighbourhoods in the city of Toronto for the year 2011.

Considering various datasets obtained from the "Open Data Toronto" repository, the authors performed very simple statistical analysis implementing a linear regression model to identify the most significantly correlated variables from the chosen datasets and the risk of debt. Even when considering this very simplified approach to the data, the authors were able to shed some light on a very serious issue affecting our modern societies, such as the risk of debt.

The quantitative indicator of debt, considered in this study, is the so called "debt indicator score" index, which was directly obtained from the publicly available datasets.

In the paper the authors report their findings, trying to argue why these make sense, although in many of the cases the explanations provided appear to be extremely simplistic, lacking of quantitatively relevant evidence or without specifying underlying assumptions. However, they present interesting discussions based on their findings trying to argue why the factors obtained as the more relevant ones according to their analysis, would make sense and fit within the datasets analyzed. The main findings of this study, are presented in Table 1 and Figure 2. After briefly describing them, the authors finalize drawing some conclusions and discussing possible ways to try to reduce the risk of debt, as well as, improve the quality of life.

It would have been interesting, for instance, to explain why the particular approach and method utilized were considered (eg. due to its simplicity, guided by the observations, even if other analyzes were performed but not relevant results were obtained, etc.) and not any other additional techniques were applied, such as, principal components analysis which also appears to be well suited for tackling similar sort of questions.

Overall, this is an interesting paper trying to tackle a quite difficult, complex, realistic and sensible issue. The authors' approach, even when simplistic, deals with real data and statistical methods that might underlie some potentially interesting factual observations, which could be considered as a very first approach to analyzing these issues, where further scrutiny is required as it is also suggested by the authors as well.

In its current version, this paper would benefit from several improvements related to aesthetics and presentation of the material (plots, appendix, etc.) in order to enhance the overall aspect of the manuscript. 